Research Article

\title{
Antimicrobial prescribing pattern in the treatment of acute respiratory tract infections in children in a tertiary care hospital
}

\author{
Vijay R. Kokani*, Prasad R. Pandit, Kiran A. Bhave
}

Department of Pharmacology, HBTMC and Dr. R. N. Cooper Hospital, Juhu, Mumbai, Mahrashtra, India

Received: 26 August 2016

Accepted: 30 August 2016

*Correspondence to:

Dr. Vijay R. Kokani,

Email: vijaykokani@gmail.com

Copyright: (C) the author(s), publisher and licensee Medip Academy. This is an openaccess article distributed under the terms of the Creative Commons Attribution NonCommercial License, which permits unrestricted noncommercial use, distribution, and reproduction in any medium, provided the original work is properly cited.

\begin{abstract}
Background: Acute respiratory infections are among the most common causes of physician consultation in the pediatric age group. Typically, the underlying etiology is viral, hence does not always requiring antibiotic prescription. However, antibiotics are often used for the treatment of many acute respiratory infections. Hence the present study was undertaken to analyse the current prescribing trends of antimicrobial use in acute respiratory tract infection in children in a tertiary care hospital and to do a quantitative analysis of overall antimicrobials used and their source.

Methods: This is a cross sectional, observational study conducted in the pediatrics inpatient department of tertiary care hospital. A total of 100 cases which included both upper respiratory tract infection and lower respiratory tract infection patients were analyzed. The total duration of study was 6 months.

Results: Penicillins were the most commonly prescribed class of drugs.

Conclusions: We noted a favourable trend towards monotherapy. All drugs in our study were prescribed by generic name.
\end{abstract}

Keywords: Acute respiratory infections, Antimicrobials, Children

\section{INTRODUCTION}

Acute respiratory infections are the leading cause of death in young children, resulting in 1.9 million childhood deaths per year in developing countries, $20 \%$ of these deaths are from India. ${ }^{1}$ Acute respiratory infections can be classified as - a) Upper respiratory tract infections (URTI) include the common cold, laryngitis, pharyngitis/tonsillitis, acute rhinitis, acute rhino sinusitis and acute otitis media, b) Lower respiratory tract infections (LRTI) include acute bronchitis, bronchiolitis, and pneumonia. ${ }^{2}$ Recent estimates suggest that the global incidence of hospital admissions in young children related to severe or very severe lower respiratory tract infections may be as high as 11.9 million (95\% CI 10.3 13.9 million) and 3.0 million (2.1-4.2 million) annual episodes respectively, representing a huge burden for the health systems, typically fragile in such settings. ${ }^{3}$
Acute respiratory infections are among the most common causes of physician consultation in the pediatric age group. ${ }^{4}$ Typically, the underlying etiology is viral, hence does not always requiring antibiotic prescription. However, antibiotics are often used for the treatment of many acute respiratory infections episodes including nonspecific symptoms such as sore throat, common cold and rhinitis or bronchospasm, for which there is an unlikely therapeutic benefit. ${ }^{5-9}$ In some cases, the symptoms are highly suggestive of a bacterial origin or with signs of severity or a pre-existing co-morbidity predisposing to bacterial infections, clearly justifies the use of antibacterial agents. Antibiotic treatment is beneficial to children only if symptoms persist for 10-14 days without improvement. ${ }^{10}$ Most instances of URTI resolve spontaneously without antimicrobial therapy according to Centre for Disease Control (CDC) guidelines. ${ }^{11}$ 
The quality of medical care requires prescribing to be judicious, appropriate, safe, effective and economic. "Good" prescribing is a complex balance between various conflicting factors. The aim is to achieve clinical benefit with minimum risk at cost effective price while respecting the patient's choice. ${ }^{12}$ The study of prescribing pattern is a component of medical audit that monitors and evaluates prescribing practices of the prescribers as well as recommends necessary modifications to achieve rational and cost effective medical care. ${ }^{13}$

Keeping these facts in consideration the present study was undertaken to analyze the current prescribing trends of antimicrobial use in acute respiratory tract infection in children in a tertiary care hospital and to do a quantitative analysis of overall antimicrobials used and their source. Findings of this study are expected to provide relevant and useful feedback to pediatricians, general practitioners and hospital administration.

\section{METHODS}

\section{Study design}

A cross sectional, observational study conducted in the Pediatrics Inpatient Department (IPD) of Tertiary Care Hospital. The total duration of study was 6 months. Periodic sample size was taken for the period of 6 months, consisting of 100 patients.

\section{Inclusion criteria}

Individuals satisfying all the following criteria were included in the study;

\section{- $\quad$ Age $\leq 12$ years}

- Diagnosed cases of acute respiratory tract infection that were prescribed antimicrobial agents.

- $\quad$ Patients willing to participate in study

\section{Exclusion criteria}

- Critically ill patients

- Patients on antitubercular therapy

- Any other systemic infection

After taking permission from the Institutional Ethics Committee (IEC) and permission of the head of the department of the pediatrics, data collection was done.

\section{Methodology}

Diagnosed cases of acute respiratory tract infection were identified and enrolled depending upon pharmacotherapy prescribed. These cases were later screened according to inclusion and exclusion criteria. Written informed consent/assent was taken. Demographic details of these patients were noted in a case record form (CRF). Prescription details were collected (drug name, route of administration, brand name, dose, duration) and prescription pattern was analyzed in the age groups $0-1$, $1-5$, above 5 years.

\section{Statistical analysis and outcome measures}

- Percentage calculation of prescription according to illness i.e. upper respiratory tract infection or lower respiratory tract infection.

- Percentage and number of prescriptions with an oral and/or injectable antibiotic prescribed.

- Percentage calculation of prescription according to each class of antibiotics and individual drug in that class.

- Percentage of FDCs (Fixed dose combination) prescribed.

\section{RESULTS}

The age group 0-1 year accounted for the highest number 58 out of 100 patients $(58 \%)$ in inpatient department (IPD). Out of 100 IPD patients 63 were boys $(63 \%)$ and 37 were girls $(37 \%)$. The age and sex distribution of inpatient cases is shown in Table $1 \& 2$.

Table 1: Age wise distribution of IPD cases age.

\begin{tabular}{|lll|}
\hline & No. of cases & Percentage \\
\hline $0-1$ year & 58 & 58 \\
\hline 1-5 years & 26 & 26 \\
\hline$>5$ years & 16 & 16 \\
\hline
\end{tabular}

(IPD: Indoor patient department)

Table 2: Sex wise distribution of IPD cases.

\begin{tabular}{|l|l|l|}
\hline Sex & Number & Percentage \\
\hline Boys & 63 & 63 \\
\hline Girls & 37 & 37 \\
\hline
\end{tabular}

\section{Clinical data}

The total number of antimicrobial agents prescribed was 100 in 100 prescriptions (Table 4) and the most common diagnosis was LRTI (Table 3). The mean number of antimicrobial agents per prescription was 1. All drugs were prescribed from the WHO essential medicine list.

Table 3: Diagnosis wise distribution of IPD cases.

\begin{tabular}{|ll|l|}
\hline Illness & Number & Percentages \\
\hline URTI & 28 & 28 \\
\hline LRTI & 72 & 72 \\
\hline
\end{tabular}

Analysis of drug prescribing pattern is given in Table 4.

The prescribing frequency of various groups of antimicrobials in patients (Table 5). Penicillins were the most commonly prescribed antimicrobial. It was given 63 patients (63\%); second most common were cephalosporins in 37 patients $(37 \%)$. 
Table 4: Prescribing indicators among inpatient cases.

\begin{tabular}{|ll|}
\hline Parameter & Numbers \\
\hline $\begin{array}{l}\text { Total number of patients prescriptions } \\
\text { analyzed }\end{array}$ & 100 \\
\hline Total number of drugs prescribed & 100 \\
\hline Average number of drugs per encounter & 1 \\
\hline $\begin{array}{l}\text { Percentage of encounter with an injection } \\
\text { prescribed }\end{array}$ & 67 \\
\hline Percentage of FDC $*$ prescribed & 63 \\
\hline
\end{tabular}

(FDC - Fixed dose combination)

Table 5: Class of antimicrobials prescribed in IPD.

\begin{tabular}{|ll|l|}
\hline Class of antimicrobial agent & URTI* & LRTI* \\
\hline Penicillin & 14 & 49 \\
\hline Macrolides & 00 & 00 \\
\hline Cephalosporin & 14 & 23 \\
\hline
\end{tabular}

(URTI: Upper respiratory tract infection, LRTI- Lower respiratory tract infection)

Amongst antimicrobial agents Amoxicillin+clavulanic acid was prescribed for 63 patients $(63 \%)$ followed by ceftriaxone 25 patients $(25 \%)$, cefixime 12 patients $(12 \%)$ (Table 6).

Fixed dose combinations were prescribed in 63 cases in inpatient department (Table 7).

Table 6: Distribution of IPD cases according to individual drug (AMA-antimicrobial agent).

\begin{tabular}{|lll|}
\hline AMAs & $\begin{array}{l}\text { No. of prescriptions } \\
\text { with AMAs* } \\
(\mathbf{n}=\mathbf{1 0 0})\end{array}$ & Percentage \\
\hline $\begin{array}{l}\text { Amoxicillin }+ \\
\text { Clavulanic } \\
\text { acid }\end{array}$ & 63 & 63 \\
\hline Ceftriaxone & 25 & 25 \\
\hline Cefixime & 12 & 12 \\
\hline
\end{tabular}

Table 7: Fixed drug combinations (FDC) prescribed in IPD cases.

\begin{tabular}{|ll|}
\hline FDC & No. of cases \\
\hline Amoxicillin + Clavulanic acid & 63 \\
\hline
\end{tabular}

In our patients, 67 were given injectable, 26 were given syrup and 7 patients were given tablets (Table 8).

Table 8: Formulations used in indoor patients in which injectable were most commonly used.

\begin{tabular}{|lllll|}
\hline & Total & Injectable & Syrup & Tablets \\
\hline No. of cases & 100 & 67 & 26 & 07 \\
\hline
\end{tabular}

All drugs prescribed were on hospital schedule. All drugs were prescribed from hospital pharmacy. All antimicrobial agents were given for 5 - 7 days.
No drug was prescribed from outside the hospital pharmacy.

\section{DISCUSSION}

The present study monitored antimicrobial prescribing patterns in patients treated for acute respiratory tract infection in the pediatric inpatient department of a tertiary care hospital. In our study, prescription of 100 IPD cases were included in study and analyzed. Penicillins were the most commonly prescribed class of drugs (63\%), while cephalosporins were the second most commonly prescribed (37\%). Amoxicillin and clavulanic acid was the most commonly prescribed antimicrobial agent from the penicillin class followed by ceftriaxone and cefixime. The predominance of penicillins use was as expected because penicillins are being recommended by most of the published guidelines (e.g. CDC, American Academy of Pediatrics). However, in a study conducted by Miti Maniar et al, macrolide was the most commonly prescribed drug class followed by penicillin (amoxicillin+clavulanic acid). ${ }^{14}$ In our study, a single antimicrobial agent was prescribed in each pre scription irrespective of the diagnosis which shows a favourable trend towards monotherapy. Conversely, a study by Naik HG et al on antibiotic drug utilization in Lower respiratory tract infections at a tertiary care hospital in Maharashtra showed $34.37 \%$ of patients on monotherapy and $65.62 \%$ patients on polytherapy. ${ }^{15}$ Usage of more than the required number of antimicrobials per patient will increase the cost of therapy, the risk of adverse events, drug interactions, and emergence of resistance and may also contribute to non-compliance by patients. Therefore it is preferable to keep the number of drugs as low as possible. All drugs in our study were prescribed by generic name which is in contrast with the study by Naik $\mathrm{HG}$ et al which had shown that brand names were used most commonly for prescribing antibiotics. ${ }^{15}$ Prescribing by generic name helps the hospital pharmacy to have a better inventory control. This will also help the pharmacy to purchase drugs on contract basis, as the number of brands is less, thus reducing the confusion among pharmacists while dispensing. Generic drugs are often more economical than the branded ones. Prescribing by brand name may be an evidence of vigorous promotional strategies by pharmaceutical companies. Regarding the prescribing of fixed dose combinations (FDCs), the present study shows that only one FDC was prescribed in study population. This FDC is from the WHO list of approved FDCs. Potential advantages of FDC's include reduced side effects, increased patient compliance, synergy and increased efficacy and reduced cost. ${ }^{16}$ Potential disadvantages include inflexible fixed dose ratio, incompatible pharmacokinetics, increased toxicity, physician and pharmacist's ignorance of contents. Most of the published guidelines do not recommend use of antimicrobials in acute respiratory tract infection as the most common etiology for acute respiratory tract infection is viral. Antibiotic treatment is beneficial to children only if symptoms persist for 10-14 days without improvement. 
The proportion of antibiotic prescription was $17 \%$ in the present study which is as per the WHO recommendation of $20 \%$ antibiotic use for these common childhood illnesses. ${ }^{17}$ This also shows that physicians in this tertiary care hospital are well aware of the guidelines regarding antimicrobial prescription. Good prescribing pattern in our study is suitably aided by the guidelines of this tertiary care hospital which are periodically updated by the administration. ${ }^{19}$ The findings are in contrast with a similar study done in Chennai, India where $79.4 \%$ children were prescribed antibiotics. ${ }^{18}$ Penicillin group was the commonest antibiotic prescribed in our study for URTI which is similar to the Chennai study.

\section{Strengths}

In our study, we have included both URTI and LRTI patients treated in inpatient department. This is in contrast with most other studies which were conducted on either URTI or LRTI patient groups singly. Pediatric population is a vulnerable population for drug exposure because of parental pressure on doctors to prescribe medicines. Hence, we have selected this population in our study so that current trends in prescribing antimicrobials in this particular group can be assessed. Our study included children with a whole spectrum of ARI disease severity, from very mild upper acute respiratory tract infections (URTI) like those with rhinitis, to severe cases of bronchiolitis and pneumonia. The sample size of our study was large, including 100 participants belonging specifically to the pediatric age group enrolled over a 06 month period. Those studies that have been larger have often looked at all ages, including adults and children, rather than looking specifically at one age group.

\section{Limitations}

The study design of the current study was a crosssectional study design. It does not allow us to understand the trend of the acute respiratory illness over time or the changes in prescribing pattern. Only those patients who were brought to hospital were included in the study. Hence, the results can only be extrapolated to a hospital based population, and may not be representative of the population as a whole.

\section{CONCLUSION}

- Most common diagnosis was lower respiratory tract infection (LRTI).

- In this study, 0-1 year age group was most common.

- Penicillin group was most frequently prescribed.

- All drugs were prescribed by generic names and were given from hospital pharmacy; hence no cost was borne by the patient for the drug therapy for acute respiratory infections.

- There was a favorable trend toward monotherapy.

\section{ACKNOWLEDGEMENTS}

Authors would like to thanks to Department of Paediatrics, TNMC and BYL Ch. Hospital, Mumbai, Maharashtra, India.

Funding: No funding sources

Conflict of interest: None declared

Ethical approval: The study was approved by the Institutional Ethics Committee

\section{REFERENCES}

1. Vashishtha VM. Current status of tuberculosis and acute respiratory infections in India: Much more needs to be done. Indian J Pediatr. 2010;47:88-9.

2. Epidemiology of acute respiratory infections. In: K Park (editor). Preventive and Social Medicine. Bhanot publishers; 2013:157-163.

3. Nair H, Simoes EA, Rudan I, Gessner BD, Azziz Baumgartner E, Zhang JS, et al. Global and regional burden of hospital admissions for severe acute lower respiratory infections in young children in 2010: a systematic analysis. Lancet. 2013;381:1380-90.

4. Mohan S, Dharamraj K, Dindial R, Mathur D, Parmasad V, Ramdhanie J, et al. Physician behaviour for antimicrobial prescribing for pediatric URTI: A survey in general practice in Trinidad, West Indies. Ann Clin Microbiol Antimicrobials. 2004;3:11.

5. Earnshaw S, Monnet DL, Duncan B, O’Toole J, Ekdahl K, Goossens H. European Antibiotic Awareness Day, 2008-The first Europe-wide public information campaign on prudent antibiotic use: Methods and survey of activities in participating countries. Euro Surveill. 2009;14:e19280.

6. Harnden A, Perera R, Brueggemann AB, MayonWhite R, Crook DW, Thomson A, et al. Respiratory infections for which general practitioners consider prescribing an antibiotic: A prospective study. Arch Dis Child. 2007;92:594-7.

7. Meropol SB, Chen Z, Metlay JP. Reduced antibiotic prescribing for acute respiratory infections in adults and children. Br J Gen Pract. 2009;59:321-8.

8. Nyquist AC, Gonzales R, Steiner JF, Sande MA. Antibiotic prescribing for children with colds, upper respiratory tract infections, and bronchitis. JAMA. 1998;279:875-7.

9. Centers for Disease Control and Prevention (CDC). Office-related antibiotic prescribing for persons aged $\leq 14$ years-United States, 1993-1994 to 2007-2008. Morb Mortal Wkly Rep. 2011;60:1153-6.

10. Rosentein N, Phillips WR, Gerber MA, Marcy MS, Schwartz B, Dowell SF. the common cold-principles of judicious use of antimicrobial agents. Pediatric. 1998;101:181-4.

11. Scott JG, Cohen D, DiCicco-Bloom B, Orzano AJ. Jaen CR, Crabtree BF: Antibiotic use in acute Respiratory infections and the ways patients 
pressure physicians for a prescription. J Fam Pract. 2001;50:853-8.

12. Martin RM. When to use a new drug. Aust Prescr. 1998;21:67-8.

13. Srishyla MV, Krishnamurthy M, Nagarani MA, Andrade C, Venkataraman BV. Prescription audit in an Indian Hospital setting using the DDD concept. Indian J Pharmacol. 1994;26:23-8.

14. Maniar M, Shah I, Rao S. Antibiotic prescription patterns in children for upper respiratory tract infections and diarrhea. JK Science. 2013;15(2):7781.

15. Naik HG, Khanwelkar CC, Kolur A, Desai R, Gidamudi S. Drug utilization study on antibiotics use in lower respiratory tract infection. National J Med Res. 2013;3(4):324-7.
16. Gupta N, Ansari KU. Fixed dose drug combinations: their uses, regulations and future prospects. Antiseptic. 1991;88:384-7.

17. WHO, the management of acute respiratory infections in children, practical guidelines for outpatient care, World Health Organization, Geneva, 1995.

18. Bharathiraja R, Sridharan S, Chelliah LR, Suresh S, Senguttuvan M. Factors affecting antibiotic prescribing pattern in pediatric practice. Indian $\mathbf{J}$ Pediatr. 2005;72(10):877-9.

19. Guidelines for antimicrobial therapy and prophylaxis. January 2014 version 1 . Available at https://www.auanet.org/education/guidelines/antimic robial-prophylaxis.cfm. Accessed on 10 August 2016.

Cite this article as: Kokani VR, Pandit PR, Bhave KA. Antimicrobial prescribing pattern in the treatment of acute respiratory tract infections in children in a tertiary care hospital. Int J Basic Clin Pharmacol 2016;5:1770-4 